\title{
Voto e Classe: notas sobre alguns estudos recentes
}

\author{
Sérgio Eduardo Ferraz \\ Doutorando do Programa de Ciência Política \\ da Universidade de São Paulo
}

\begin{abstract}
Resumo. Este artigo apresenta uma inflexão na literatura acadêmica desafiadora do consenso, firmado nas décadas de 1980 e 1990, em torno da ideia da perda de importância relativa das clivagens sociais e, em especial, classistas, enquanto variável explicativa do comportamento eleitoral em democracias avançadas. O texto apresenta e discute amostra de recentes pesquisas internacionais que convergem na revalorização da classe social enquanto fonte de orientação do voto e sublinha a importância atribuída por essa nova literatura à questão metodológica e ao reexame da informação empírica coletada nas últimas décadas sobre o voto, destacando alguns dos resultados obtidos que sugerem uma nova compreensão da relação entre classe e sufrágio nas democracias maduras.
\end{abstract}

Palavras-chaves: clivagens; estudos eleitorais; comportamento politico; voto; classe social

Abstract. This article aims to provide an approach on a possible inflexion ongoing in contemporary electoral comparative studies, challenging the consensus reached in the 1980s and 1990s around the idea of the loss of the relative importance of social divisions and, in particular, classists, as the explanatory variable of electoral behavior in advanced democracies. In that sense, the text presents and discusses samples of recent international studies that converge on the revaluation of social class as a source of guidance on vote. It is pointed out the attributed importance by this new literature on the methodologic question and in the review of empirical information collected in the last decades by vote, especially some of the results that suggest a new understanding of the relationship between class and suffrage in mature democracies.

Key-words: clivages; electoral studies; political behavior; vote; social class

\footnotetext{
${ }^{1}$ Agradeço ao professor André Singer pelas sugestões feitas ao presente trabalho.
}

OPINIÃO PÚBLICA, Campinas, vol. 15, no 2, Novembro, 2009, p.451-477 


\section{Introdução}

O presente artigo tem por objetivo central a apresentação de uma amostra da recente literatura, situada no âmbito dos estudos eleitorais, que argumenta em favor da revalorização da classe social como fator de substantiva importância na estruturação das preferências político-eleitorais dos cidadãos das democracias contemporâneas. Esses estudos contestam um amplo consenso, firmado nas décadas de 1980 e 1990, em torno da ideia do esvaziamento ou enfraquecimento das clivagens sociais e, em especial, classistas, enquanto fonte de explicação do comportamento eleitoral na maior parte das democracias maduras. Os textos representativos da amostra referida são os seguintes: MANZA, HOUT e BROOKS (1995); MANZA e BROOKS (1996); EVANS (2000); van DER WAAL, ACHTERBERG e HOTMAN (2007) e ELFF (2007)

As novas pesquisas que desafiam o acordo prevalecente sobre a tendência histórica do declínio do voto de classe são heterogêneas, mas convergem em um ponto crucial, a saber, a centralidade da questão metodológica e do reexame da informação empírica como passo preliminar fundamental para averiguar a importância maior ou menor da política de classe nas sociedades democráticas avançadas. Em termos sintéticos, para esse último grupo de analistas, a geração anterior de estudos utilizou modelos, técnicas e indicadores estatísticos permeados por um grande número de deficiências, os quais se revelariam, à luz de um escrutínio crítico, completamente inadequados para lastrear, do ponto de vista científico, os achados alegados por seus usuários. Sobretudo, a substituição dessa metodologia por tratamentos mais sofisticados seria capaz de produzir notável inflexão nas conclusões sustentadas no interior do campo dos estudos eleitorais quanto à importância da classe em uma considerável reviravolta frente ao que até recentemente se erigia como new conventional wisdom.

Para fins do presente artigo, pode-se afirmar que a reflexão na teoria social sobre as relações entre o sufrágio e a classe social atravessou, desde o período posterior à Segunda Guerra Mundial, três grandes períodos ou ondas, marcados por distintas avaliações sobre a matéria. Com base nisso, este artigo divide-se em duas grandes seções. A primeira traça, em linhas gerais, as duas primeiras fases da pesquisa sobre voto e classe, por meio das quais se transita de uma perspectiva que enfatiza as relações entre clivagens sociais e dinâmica político-eleitoral para um ponto de vista que indica o declínio dessa associação, conformando o consenso já referido sobre o eclipse das clivagens classistas na política do capitalismo pósindustrial. Essa primeira seção, por conseguinte, estrutura o cenário de fundo a partir do qual se desenvolveram, nos últimos anos, os novos estudos revalorizadores da classe social. Na segunda seção, são expostas algumas das principais críticas metodológicas, sustentadas pelos novos analistas da relação 
classe e voto frente à onda anterior de reflexão, bem como sumarizadas as conclusões de pesquisas alicerçadas em novos métodos, de modo a fornecer uma ideia do perfil do trabalho que vem sendo produzido por esses autores.

Este artigo não pretende realizar uma revisão exaustiva dos estudos correntes sobre voto e classe tão-pouco empreender uma discussão crítica e pormenorizada das várias tendências existentes na pesquisa atual. Isso, certamente, confere ao artigo certo desequilíbrio e, talvez, certa aderência excessiva aos posicionamentos da literatura revalorizadora da classe social, o que, espera-se, não elimine alguma utilidade que ele eventualmente possa ter.

\section{Do Consenso Pós-Segunda Guerra à Literatura sobre o Declínio do Voto de Classe}

Do ponto de vista dos estudos sobre a relação entre classe social e voto, prevalecia entre os especialistas, na virada dos anos 1960, a noção de que a posição de classe tinha um substancial grau de influência na escolha eleitoral, conquanto sujeito a variações no tempo e entre países. Essa perspectiva refletia o pressuposto corrente mais geral a respeito do condicionamento da competição política pelas estruturas sociais. Uma importante expressão desse consenso veio a ser a síntese teórica escrita por Lipset e Rokkan como introdução ao clássico volume Party Systems and Voter Alignments publicado em $1967^{2}$. Nela, os dois autores destacavam os papeis chave desempenhados pelo processo de statebuilding e pela revolução industrial na conformação dos principais tipos de clivagens presentes nas democracias políticas do capitalismo avançado contemporâneo, a saber, igreja/Estado, culturas dominantes/culturas minoritárias, economia primária/secundária e patrões/empregados. Ainda que o peso relativo e a articulação exata dos quatro tipos mencionados de clivagens tenham variado em cada país, por conta de fatores históricos específicos, teríamos aqui a delimitação de um padrão estrutural de clivagens responsável pelos contornos básicos do conflito sociopolítico associado à trajetória de modernização de cada uma das sociedades ocidentais mais avançadas. Finalmente, o avanço ulterior da industrialização teria emprestado peso especial à clivagem de classe . patrões/empregados -, tornando-a fator chave para a compreensão da dinâmica político-eleitoral desses sistemas (MANZA, HOUT e BROOKS, 1995, p. 141) ${ }^{3}$.

\footnotetext{
2 LIPSET e ROKKAN (1967).

3 Sobre as pressuposições dominantes nos estudos eleitorais europeus por volta dos anos 1960 acerca das relações entre estrutura social e política, escreve Martin Elff: "A influência das características sociais no voto esteve (...) presente desde o começo na agenda da pesquisa eleitoral. Uma suposição comum no estudo da política comparada até [a década] de 1960 era que características sociais tais como classe, religião, identidades regional e étnica eram os principais condicionantes da decisão do voto na Europa Ocidental. (...). Os partidos da Europa Ocidental eram frequentemente percebidos como representativos de certos estratos sociais ou grupos de interesse. Partidos social-democráticos, socialistas e comunistas, por exemplo, eram vistos enquanto representantes da classe trabalhadora industrial. Por outro lado, o apoio aos partidos por certos grupos
} 
Quanto ao sufrágio nas democracias ocidentais, desde a década de 1930 uma crescente massa de estudos eleitorais havia sugerido, por diversos meios, a existência de substantiva correlação entre posição de classe e comportamento eleitoral, tornando-se essa associação objeto de sólido consenso entre a maior parte dos especialistas na passagem entre as décadas de 1950 e 1960 - marcadamente após a disseminação das pesquisas baseadas em sondagem direta de opinião pública ou surveys (ALFORD, 1967, p. 67.8). Manza, Hout e Brooks sublinham, por seu turno, que o acúmulo de surveys aplicados em eleições nacionais, no âmbito das democracias avançadas, desde os anos 1960, permitiu o exame detalhado de diversas hipóteses a respeito da associação voto-classe durante um período de tempo relativamente extenso (MANZA, HOUT e BROOKS, 1995, p.141). Nesse sentido, emergiram diversas formulações: para alguns, o voto de classe afirmar-seia como simples expressão de interesses materiais, isto é, como expressão racional do autointeresse; para outros, enquanto resultado de socialização, do pertencimento a determinados grupos sociais e dos efeitos de reforço de lealdades derivados das redes intraclassistas de relacionamento social; em uma terceira visão, esse tipo de voto deveria ser pensado como uma das etapas iniciais, em termos temporais e causais, da decisão do voto estruturada enquanto uma cadeia em forma de funil ${ }^{4}$.

Dentre os estudos eleitorais específicos que marcaram o assinalado consenso pós-1945, destaca-se o trabalho de Robert Alford (1963; 1967, p. 67-93). Para Evans (2000, p. 404-5), a análise de Alford sobre tendências nos padrões de voto classista em quatro democracias do mundo anglo-saxão (Austrália, GrãBretanha, Canadá e Estados Unidos) tornou-se o ponto de referência ou marco básico para toda uma era de subsequentes estudos comparativos do voto de classe. Examinando dados empíricos relativos ao período 1936-1962. Alford utilizou uma medida de posição socioeconômica na qual as ocupações eram agregadas de modo a formar uma dicotomia entre o trabalho manual e o não-manual e uma medida do voto que também dicotomizava as opções entre esquerda e direita. Operacionalizando a partir dessas medidas a relação classe-voto, Alford criou o mais conhecido índice de mensuração do tipo de voto em foco, o qual passou a levar seu nome na extensa literatura subsequente. O Índice Alford de Voto de Classe é obtido da seguinte maneira: do percentual de trabalhadores manuais que votam em partidos de esquerda, subtrai-se o percentual de pessoas, em ocupações nãomanuais, que também optam eleitoralmente por aquelas agremiações. 0 resultado da operação fornece o Índice de Voto de Classe. Por exemplo, se $70 \%$ dos

sociais era dado como certo. Pressupunha-se, por exemplo, que os trabalhadores britânicos votariam nos Trabalhistas e não nos Conservadores, enquanto que os trabalhadores franceses votariam no Parti Socialiste ou nos comunistas, mas não nos Gaulistas" (ELFF, 2007, p. 277).

${ }^{4}$ Manza, Hout e Brooks associam essas hipóteses às Escolas de Columbia e de Michigan e aos seguintes trabalhos: DOWNS (1957) e LIPSET LAZARSFELD; BARTON. e LINZ (1954). 
trabalhadores manuais de um país votam no partido da esquerda e $20 \%$ dos indivíduos empregados em ocupações não manuais também o fazem, então o Índice é 50 (ALFORD, 1967, p. 80-1).

Em seu conhecido trabalho publicado na coletânea editada por Lipset e Rokkan (1967), Alford chegou a conclusões que sintetizaram o "estado da arte" desse campo de estudos no final da década de 1960. Enfocando quatro países anglo-saxões - Grã-Bretanha, Austrália, EUA e Canadá -, o autor mostrou que era possível identificar padrões estáveis do voto classista em cada uma das sociedades estudadas, classificando-as em ordem decrescente de acordo com a intensidade da associação classe-voto. Nesse sentido, sua pesquisa mostrou que, entre as décadas de 1940 e 1960, o voto de classe foi consistentemente mais alto na Grã-Bretanha e Austrália do que nos Estados Unidos e no Canadá (índices médios, respectivamente, de 40, 33, 16 e 8), sendo reiteradas as conclusões depois de submetidos os dados a vários tipos de controle - faixa etária, religião, urbanização, diferenças regionais etc - (ALFORD, 1967, p.82-84).

Esse acordo a respeito da importância das clivagens sociais e, em particular, dos conflitos de classe para a compreensão do processo político das democracias avançadas entrou, no entanto, em um notável declínio a partir de meados da década de 1980 (MANZA, HOUT e BROOKS, 1995, p. 138-41; 1996, p. 718-9; EVANS, 2000, p. 402-5; ELFF, 2007, p. 277-8). Desde então, o consenso referido tem estado sob sério ataque, em função de "reveses experimentados por partidos social-democratas ou trabalhistas, da emergência de movimentos políticos de caráter religioso, nativista e regional [ressuscitando clivagens desde muito pensadas como desativadas politicamente] e da súbita aparição de 'novas' questões, tais como as preocupações ecológicas e antinucleares" (MANZA e BROOKS, 1996, p. 719; MANZA, HOUT e BROOKS, 1995, p. 141). Foi, portanto, a partir desse cenário de crescente questionamento da visão até então dominante que se multiplicaram estudos na literatura especializada apontando o declínio da importância política das classes, a abertura do eleitorado a novos apelos não vinculados a uma referência classista, bem como a emergência de uma política calcada agora em valores pós-materialistas - ou que não se mostrava inteligível a partir das antigas clivagens. Nesse novo contexto, a estável dinâmica política lastreada, por muito tempo, na competição entre classes, típica do capitalismo industrial, estaria sendo substituída, nas últimas décadas, por um cenário onde se destacariam novas divisões ligadas ao "gênero, à identidade e aos valores" (MANZA, HOUT e BROOKS, 1995, p. 138). Adicionalmente, a dissociação entre classe e voto (o fenômeno do dealignment), ao lado do declínio da saliência política de outras clivagens sociais, estaria na base da crescente "instabilidade política [que se expressaria mediante o surgimento] de novos movimentos políticos, novos partidos e mesmo de (...) [lideranças pessoais]", os quais, em comum, possuiriam a 
característica de se divorciarem completamente dos canais políticos tradicionais, em especial dos sistemas partidários ali gestados (MANZA, 1995, p.138).

Examinando esse processo de declínio da importância atribuída pela literatura às clivagens sociais e, em especial, à classe como elemento estruturador das preferências políticas, Evans aponta o substantivo uso, por esses estudos, do indicador de Alford (e de medidas correlatas), o qual, quando aplicado a períodos posteriores à análise clássica de seu criador, revelaria resultados inversos aos originais, comprobatórios agora do esvaziamento progressivo e tendencial do conteúdo de classe do sufrágio (EVANS, 2000, p. 404-5). Segundo esse autor, a utilização do Índice Alford transformou-se em um procedimento padrão característico de uma vasta literatura dedicada à análise histórico-comparativa dos padrões do voto de classe, a qual conformou, em seus termos, "the two class/two party era" (EVANS, 2000, p. 404-5). Resumindo essa era de estudos, escreve Evans:

"[o conjunto de estudos tributários do Índice de Alford e outros indicadores correlatos] concluiu que o voto de classe está em declínio. Lipset (...) apresentou evidências de uma tendência declinante na GrãBretanha, Alemanha e Estados Unidos entre 1945 e 1980. Inglehart (...) encontrou evidência adicional de um contínuo declínio a partir da década de 1980; Sainsbury (...) e Listhaug (...) [constataram] declínio no voto de classe nos países escandinavos; Lane e Erson (...) descobriram [níveis inferiores] de voto de classe em nove nações industrializadas [nas décadas] de 1970 e 1980 [quando comparadas] com [as décadas] de 1950 e 1960, [deparando-se] com [padrões mais significativos] de voto de classe em somente duas nações (França e Itália). A exaustiva revisão de Nieuwbeerta (...) forneceu muitos outros exemplos [da trajetória em questão]. A partir desse tipo de evidências, Clark e Lipset (...) concluíram, no início dos anos 1990, que a política 'hoje é menos organizada pela classe e mais por outras lealdades'. Essa posição foi (...) [por sua vez] endossada por um extenso estudo comparativo acerca de mudanças eleitorais e do declínio [do papel das] clivagens [sociais] na política compilado por Franklin et al (...). Esse projeto modelou o comportamento eleitoral (esquerda versus não-esquerda) em nada menos do que dezesseis países, incluindo como variáveis explicativas a posição de classe [manual/não manual] e características sociais tais como religião, filiação sindical, sexo, educação e orientações sobre valores e questões específicas. Ele representou o ápice da [era two-class/two party]. [Sintetizando as conclusões da pesquisa], (...) Franklin observou que 'quase todos os países [estudados] (...) mostram um declínio (...) na capacidade das 
clivagens sociais de estruturar a escolha individual do voto" "5 (EVANS, 2000, p. 404-5).

Evans conclui que, diante desse amplo rol de estudos, para muitos analistas, o declínio do voto de classe deixou de ser matéria controversa, não causando surpresa o fato de que alguns mais extremados tenham chegado a proclamar a "morte" da política de classe (EVANS, 2000, p. 405) ${ }^{6}$.

Concordando com Evans no que concerne a que extensões o Índice Alford têm representado, em grande medida, o lastro metodológico da literatura que aponta o declínio do voto de classe, Manza, Hout e Brooks (1995, p. 141-2) buscaram organizar as principais evidências arroladas pelos estudiosos para sustentar essa posição. Uma primeira evidência decorreria diretamente da aplicação do índice a períodos mais recentes em diversos países capitalistas democráticos maduros. Nesse sentido, a leitura do Gráfico 1 indica, nitidamente, o enfraquecimento do voto classista, nos termos de mensuração propostos por Alford, para importantes democracias ocidentais. Na Suécia, Grã-Bretanha e Estados Unidos, transita-se de um índice situado entre 40 e 50\%, à época do pós-Segunda Guerra, para patamares respectivos de $30 \%, 20 \%$ e $10 \%$ em meados da década de 1980. Também na Alemanha e França, constata-se uma tendência à fragilização do caráter de classe do sufrágio, materializado em uma trajetória que, partindo de níveis de $30 \%$, na década de 1950 , recua para $10 \%$ e 15\%, respectivamente ${ }^{7}$.

\footnotetext{
${ }^{5}$ As referências dos trabalhos citados por Evans são as seguintes: Clark e Lipset (1991); Inglehart (1990); Sainsbury (1987); Listhaug (1997); Lane e Erson (1994); Nieuwbeerta (1995); Valen et al (1992).

6 Sobre o mesmo fenômeno, escreve Elff: “(...) A perspectiva socioestrutural da política tornou-se ultrapassada em décadas recentes. Em seu lugar, achados como os de Franklin et al [os quais atestam] que 'quase todos os países que estudamos mostram um declínio (...) na capacidade das clivagens sociais de estruturar a escolha individual do voto', adquiriram o status de um novo saber convencional" (ELFF, 2007, p. 277).

${ }^{7}$ A literatura que se baseou no uso do Índice Alford para demonstrar o declínio do voto de classe entre 1947 e 1986 é sumariada e criticada também por van der Wall, Achterberg \& Houtman (2007). 0 primeiro texto a estruturar um gráfico como o apresentado no texto acima foi o de Clark e Lipset (1991).
} 


\section{Gráfico 1}

Índice Alford de Voto de Classe declinante ao longo do tempo

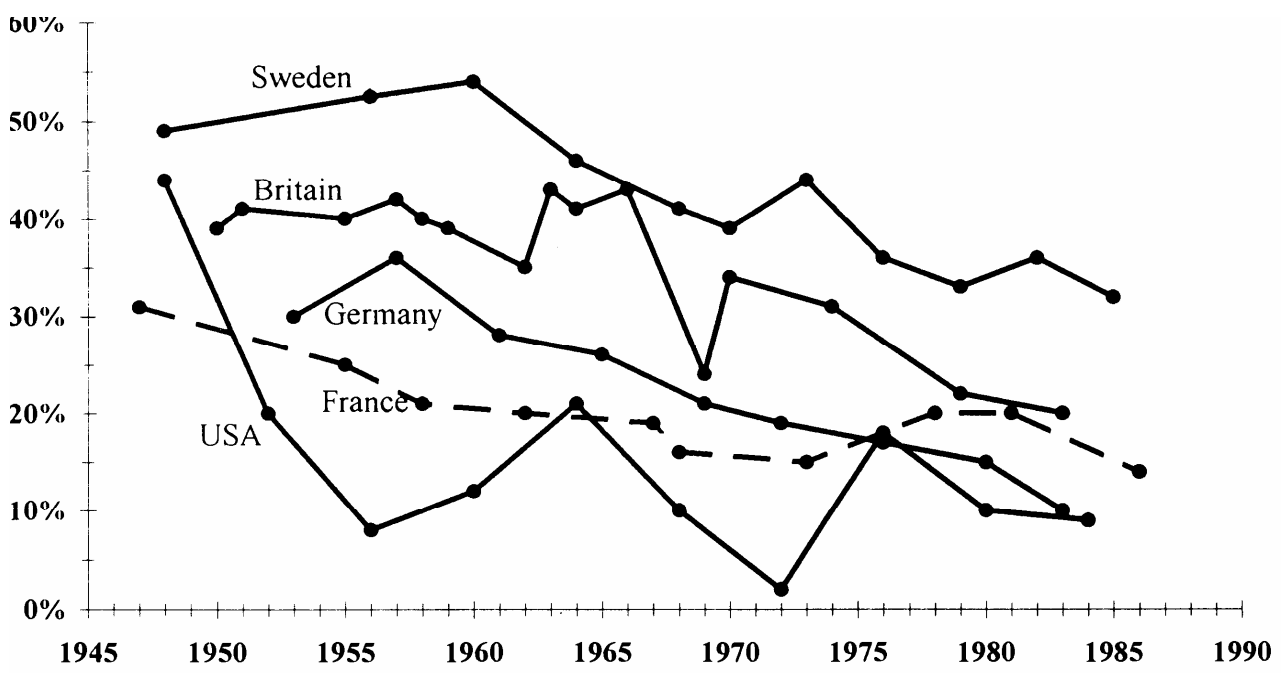

Fonte: Reproduzido de MANZA, HOUT e BROOKS, 1995, p. 142.

Um segundo tipo de evidência utilizado para lastrear o argumento do declínio tem sido o chamado nível absoluto do voto de classe, definido, para o caso da Grã-Bretanha, como a proporção sobre o total de votos da soma entre os sufrágios conservadores oriundos das "classes médias" e os sufrágios trabalhistas oriundos da "working class" (MANZA, HOUT e BROOKS, 1995, p. 142). O pressuposto é que cada classe possuiria o seu partido "natural". Na medida em que os estudos indicam que, nas últimas décadas, uma menor proporção de eleitores tem optado por seu respectivo partido natural, a conclusão é que o nível absoluto do voto classista tem diminuído ${ }^{8}$.

Um terceiro grupo de pesquisadores tem utilizado, na mensuração do mesmo fenômeno, modelos estatísticos multivariados no intuito de aferir eventuais mudanças no poder preditivo líquido da classe quanto à escolha eleitoral, confrontando esse poder preditivo com aqueles associados a outras variáveis sociais estruturais ${ }^{9}$. Em que pese a heterogeneidade dos resultados desses estudos entre países e, no âmbito de um mesmo país, entre diferentes pleitos eleitorais, a conclusão predominante é que os resultados das regressões sugerem "que a classe explica uma proporção reduzida da variação [do voto] em eleições recentes (...)

8 Manza, Hout e Brooks citam, entre outros, como exemplos dessa abordagem, os estudos de CREWE (1986) e ROSE (1986).

${ }^{9}$ Aqui os estudos de referência são os capitaneados por Mark N. Franklin e Thomas Mackie (1992). 
declinando em importância [para a compreensão] do comportamento político". Aqui se verificaria, na verdade, um processo de longo prazo, abrangendo, com temporalidades diferenciadas, todas as democracias avançadas, cujo ponto de chegada indicaria claro eclipse da relevância das principais clivagens sociais estruturais na explicação das razões de variação do voto, com efeitos de incremento da volatilidade e da incerteza nos prospectos político-eleitorais desses países (FRANKLIN e MACKIE, 1998, p. 78.84; MANZA, HOUT e BROOKS, 1995, p. 143).

Para além da apresentação de evidências que alegadamente sustentariam o argumento acerca do declínio do voto classista, os estudiosos comprometidos com esse ponto de vista desenvolveram explicações sobre as razões subjacentes à perda da importância da classe - e das clivagens sociais em geral - na política democrática contemporânea. Tanto Manza, Hout e Brooks (1995) como Evans (2000) consideram ser possível dividir as explicações sobre o declínio do voto de classe, presentes nessa literatura, em cinco grandes tipos, sintetizados a seguir ${ }^{10}$.

1. Um primeiro argumento remete aos efeitos da sustentada prosperidade econômica experimentada pelas democracias capitalistas do ocidente nas décadas subsequentes ao término da Segunda Guerra Mundial, gerando crescente riqueza e afluência que elevou os padrões de vida das classes trabalhadoras e dos lower-level white-collar workers, abrindo caminho para o que muitos estudiosos identificaram como um processo de "aburguesamento" das massas trabalhadoras. Relacionando. se com essas transformações, outros autores enfatizaram os efeitos da crescente mobilidade social e ocupacional no comportamento político, apontando sua contribuição para o declínio do voto de classe. Indivíduos móveis social e ocupacionalmente tenderiam a adotar pontos de vista político-ideológicos intermediários entre os seus estratos de origem e de destino, mediante processos de aculturação, tornando flexíveis e matizadas as tradicionais lealdades "fechadas" de classe. Em síntese, o pertencimento originário a uma classe social determinaria no capitalismo contemporâneo, em especial a partir do pós-guerra, em muito menor grau as chances de vida de um indivíduo, perdendo boa parte de sua força enquanto determinante dos interesses e das preferências políticas;

2. Um segundo grupo de ideias foca a emergência de novas formas de divisões sociais nas democracias avançadas, as quais, paulatinamente, substituíram ou, pelo menos, minimizaram notavelmente o papel da classe como fonte de clivagem política. Sublinha-se, assim, a crescente importância na contemporaneidade de clivagens sociais caracteristicamente pós-industriais - gênero, raça, etnia, identidade, etc ', sendo esses novos fatores de diferenciação social mais

${ }^{10}$ A literatura pertinente a cada um dos tipos explicativos assinalados está indicada em Manza, Hout e Brooks (1995, p. 143-50) e em Evans (2000, p. 405-6). 
importantes para o entendimento do conflito contemporâneo e para a determinação do comportamento eleitoral do que a polarização tradicional patrão-empregado;

3. Um terceiro conjunto de argumentos explica o esvaziamento da classe enquanto fonte das preferências eleitorais como função da maior capacidade de escolha política autônoma de cidadãos dotados de um patamar mais elevado de recursos educacionais. Eleitores com mais ativos educacionais e culturais (mais "mobilizados cognitivamente", no jargão de parte dos analistas) tenderiam, progressivamente, a avaliar plataformas políticas de forma mais racional, centrando-se em issues específicas e procurando refratar a agenda pública a partir de um escrutínio mais atento de seu grau de compatibilidade frente aos próprios interesses. 0 enfraquecimento de lealdades partidário-classistas equivaleria, nesse tipo de análise, a uma espécie de descarte de prévias muletas analíticas, tornadas desnecessárias pelo incremento dos padrões educacionais modernos, dando ensejo, também, a uma competição política mais aberta - no sentido de menos condicionada por constrangimentos estruturais apriorísticos;

4. Outra linha explicativa enfatiza o papel dos valores como base fundamental para a conformação de preferências partidárias nas sociedades avançadas contemporâneas, tendo um papel corrosivo sobre as antigas clivagens de classe por força de seu caráter cross-cutting. Essa linha de raciocínio aponta com ênfase a emergência de uma agenda valorativa pós-materialista, fortemente apoiada por setores de classe média, resultando em uma reconfiguração do contínuo tradicional esquerda-direita associado às clivagens de classe;

5. Finalmente, uma última corrente busca entender os processos de enfraquecimento do voto classista a partir de modelos explicativos macroestruturais, os quais enfatizam transformações na dinâmica capitalista global e mudanças nas estratégias partidárias. Aqui, na verdade, observam-se duas linhas explicativas distintas. A primeira ecoa o chamado "dilema eleitoral" do socialismo, nos termos originalmente propostos por Przeworski (1989). Na síntese de Evans:

\footnotetext{
"uma vez que a classe trabalhadora manual decresceu como proporção do eleitorado, os partidos de esquerda tiveram que direcionar seus programas [rumo às] preocupações das crescentes classes médias sob pena de derrota eleitoral (...). Eles moderaram, por conseguinte, o caráter de classe de seu apelo político e enfraqueceram a distinção classista das escolhas políticas [confrontadas] pelo eleitorado" (EVANS, 2000, p.406).
} 
Nesse argumento, as escolhas estratégicas político-partidárias frente a dilemas eleitorais, em um contexto societário marcado pela expansão numérica das classes médias, foram responsáveis, pelo menos parcialmente, pelo declínio do voto de classe. A segunda família de argumentos de cunho estrutural foca sua lente analítica nos efeitos disruptivos das novas formas organizativas do capitalismo global para a solidariedade de classe e para a estabilidade dos alinhamentos eleitorais de natureza classista, em particular a partir do início da década de 1980. Nesse sentido, as rápidas mudanças nas estruturas econômicas, decorrentes da revolução nas comunicações e nos transportes, em um contexto de liberalização de mercados, conduziram à destruição e criação de setores, ao deslocamento em massa de capitais e à transformação de regiões. Todo esse processo, do ponto de vista sociopolítico, abriu espaço para novos conjuntos de cross-cutting cleavages e "enfraqueceu a saliência das divisões tradicionais de classe" (MANZA, HOUT e BROOKS, 1995, p.147). A própria crise dos esquemas de proteção social e o avanço dos mecanismos de mercado, no seio das democracias maduras, teria posto em xeque a hegemonia da social-democracia perante as camadas de base da sociedade, dando ensejo a novas fragmentações.

Delineado esse quadro geral da reflexão sobre as relações entre voto e classe desde os anos 1960 até a literatura emergente a partir da década de 1980, que assinala o declínio da importância das clivagens sociais estruturais, é hora de passar aos argumentos substantivos de alguns textos representativos da nova onda de resgate do papel da classe no processo político contemporâneo. A estratégia desses textos, curiosamente, se volta menos para uma contestação direta das razões pretensamente subjacentes à perda de importância da classe na política, alinhavadas acima, do que para o enfrentamento das premissas metodológicas que geraram, inicialmente, as alegadas evidências do esvaziamento do caráter classista do voto ${ }^{11}$. Trata-se, portanto, para a linha de pesquisa revalorizadora da classe, de voltar um passo atrás no debate e desafiar as conclusões extraídas da leitura dos dados sobre o voto, realizada pelos estudos defensores do esvaziamento das clivagens estruturais. É desse desafio que a próxima seção trata.

\footnotetext{
11 Naturalmente, todas as cinco linhas de argumentação recebem contestação da parte de amplo grupo de estudiosos, os quais ultrapassam em muito o âmbito daqueles simpáticos à revalorização da classe. Manza, Hout e Brooks (1995, p. 147-150) enumeram ponto por ponto as principais respostas e qualificações às teses apresentadas como razões explicativas do declínio do voto de classe. Elff, por sua vez, critica com vigor a tese da mobilização cognitiva e empresta outra leitura à parte dos argumentos macroestruturais $(2007$, p. 284-6; 288-90). No entanto, o que se quer destacar aqui é que o eixo central da estratégia da literatura revalorizadora da classe chega a essas questões apenas indiretamente, porquanto se volta, em primeiro lugar, para o ataque aos próprios postulados metodológicos produtores da evidência original que aquelas razões pretendem explicar. Em outras palavras, para os analistas que contestam a literatura do declínio, a interpretação mesma dos dados embasadora do alegado enfraquecimento da clivagem classista é, em essência, fruto de tratamento estatístico deficiente.
} 


\section{A Nova Literatura Revalorizadora da Classe: uma Amostra dos Estudos Recentes}

A nova literatura, emergente a partir da década de 1980, que contesta o saber convencional e revaloriza o papel da classe como condicionante de substantiva importância das preferências políticas percorre diferentes trilhas argumentativas, convergindo, no entanto, em um ponto de partida: a centralidade da questão metodológica e do reexame da evidência empírica na crítica à tese do declínio dos padrões classistas de sufrágio (MANZA, HOUT e BROOKS, 1995; MANZA e BROOKS, 1996; EVANS, 2000; van DER WAAL, ACHTERBERG e HOUTMAN, 2007; ELFF, 2007). Para esses autores, o diagnóstico acerca da importância da política de classe nas sociedades democráticas avançadas depende, essencialmente, do rigor e da qualidade dos métodos estatísticos e das técnicas de mensuração utilizadas para o tratamento e análise dos dados empíricos pertinentes. A questão crucial, na formulação de Evans (2000, p. 406), é que os métodos e técnicas utilizados pelos defensores do enfraquecimento das clivagens classistas, inspirados em grande parte no Índice Alford e em indicadores dele derivados, embutem deficiências e se revelam completamente inadequados para lastrear os achados alegados por seus usuários. Mais importante ainda, a sua substituição por tratamentos mais sofisticados vem produzindo inflexões nas conclusões sustentadas no interior desse campo de estudo, promovendo uma considerável reviravolta ao que se conhecia como new conventional wisdom no campo dos estudos eleitorais (ELFF, 2007, p. 277). Essa seção realiza uma incursão por questões metodológicas levantadas pelos estudiosos em foco, apontando as diferentes conclusões sobre o status da classe nas democracias contemporâneas alcançadas por pesquisas beneficiadas por técnicas estatísticas inovadoras. Em seguida, o artigo dá alguma atenção à agenda proposta para futuros estudos por alguns dos defensores do resgate da classe. Para todos esses pontos, a referência central, embora não exclusiva, é o trabalho de Evans (2000). No final da seção, o foco transita para a exposição da inventiva e estimulante contribuição ao debate trazida por van der Waal, Achterberg e Houtman (2007).

No que concerne aos aspectos metodológicos, é corrente entre o grupo de estudiosos examinado nesta seção a crítica ao Índice Alford. Para Manza e Brooks (1996), por exemplo, em que pese ter representado, ao seu tempo, uma "brilhante inovação" (MANZA e BROOKS,1996, p. 720) no campo dos estudos eleitorais, o índice Alford não pode hoje ser considerado uma medida aceitável do voto de classe em função de suas duas características centrais: a divisão da sociedade em duas classes (trabalhadores manuais versus trabalhadores não manuais) e a divisão de sistemas partidários em dois campos (esquerda versus direita). Tais características ensejam óbvios problemas: onde situar, por exemplo, nesse modelo classista dicotômico, os amplos e diversificados estratos intermediários, que ampliaram 
notavelmente sua importância nas sociedades industriais avançadas das últimas décadas? Por outro lado, como assinalam os dois autores referidos, a dicotomia partidária embutida no índice também suscita problemas cuja resolução, nos estreitos limites do indicador em foco, conduz a claras distorções; nesse sentido, parece problemático imputar posições de esquerda ou de direita a novos partidos ou a agremiações centristas, em especial "quando as questões que definem suas plataformas são multidimensionais" (MANZA e BROOKS, 1996, p. 720). Por conta dos problemas apontados, o Índice de Alford não se prestaria a mensurar mudanças seja na evolução histórica dos partidos seja nas suas bases de classe. Sobretudo, esse indicador também não seria hábil a distinguir entre o fenômeno de realinhamento - mudança estrutural nas bases de classe do apoio partidário - e o que os autores denominam de "dealignment", o qual traduziria a independência estatística, ou seja, a não associação/correlação, entre pertencimento a uma classe e apoio partidário. Essas insuficiências do Índice Alford (e de indicadores correlatos), porém, são conhecidas desde a década de 1970 e podem ser corrigidas com o conhecimento técnico disponível, o que torna injustificável a sua utilização nos moldes tradicionais por pesquisadores que pretendem com isso "demonstrar" o declínio do voto de classe.

Abordando inovações metodológicas recentes, Evans (2000) examina propostas de operacionalização da posição de classe e das preferências políticas bem como técnicas aperfeiçoadas para a estimação da associação entre as duas variáveis. No que tange à posição de classe, uma das principais deficiências associadas à distinção dicotômica entre trabalhadores manuais e não-manuais é que qualquer mudança na composição de uma das duas categorias pode gerar mudanças espúrias nas estimativas do voto de classe. Um exemplo: se aumenta a proporção de trabalhadores manuais de alta qualificação no lado pertinente da dicotomia, e se esse subgrupo de trabalhadores costuma sustentar posições políticas mais conservadoras do que a média dos trabalhadores manuais, decresce o voto classista, na hipótese de esse estar sendo mensurado em termos do Índice Alford, ainda que as preferências políticas relativas dos qualificados, não. qualificados e dos não manuais permaneçam idênticas.

Nos últimos anos, porém, esquemas de classe mais refinados foram desenvolvidos, permitindo a superação de muitas das desvantagens geradas pelas técnicas tradicionais. Segundo Evans, destaca-se, entre essas inovações, o modelo proposto por Goldthorpe, que distingue quatro tipos de posições de classe: a pequena burguesia (pequenos empregadores e autônomos), a classe assalariada (que não se confunde com a classe trabalhadora tradicional e é composta por pessoal ligado a funções técnicas e gerenciais, concentrando as camadas mais bem posicionadas entre os antigos não-manuais), os não-manuais responsáveis por serviços de rotina (basicamente, os níveis inferiores no interior do grupo dos não. 
manuais, isto é, os chamados lower grade white-collar workers) e, finalmente, a working-class (dividida entre distintos níveis de responsabilidade nos locais de trabalho e por grau de qualificação). Uma das vantagens de um esquema assim matizado é que ele permite a incorporação de distinções importantes por suas implicações políticas. Nesse sentido, entre o grande grupo dos empregados a diferença mais importante se daria entre os que se vinculam ao trabalho mediante o que Evans denomina, com base no esquema em foco, de "service contract" (concentrados na classe assalariada) e os que estão sujeitos a um "labor contract" (níveis inferiores dos não manuais e working-class). Os primeiros "recebem não apenas (...) salários, mas [contam] também [com] elementos prospectivos [no âmbito de sua remuneração] - incrementos de renda, [maior] segurança no emprego, [esquemas de] pensões e, mais importante, perspectivas bem definidas de oportunidades de carreira" (EVANS, 2000, p. 407). Já os segundos ofertam, sob supervisão, quantidades definidas de trabalho, em troca de salários calculados em termos de tempo emprestado para o empregador, aproximando-se das condições clássicas do trabalho assalariado estudadas desde a obra de Marx. Dessa distinção decorrem evidentes implicações políticas: o grupo vinculado aos "service contracts" tende a reter um claro interesse na preservação do status-quo, por força de sua posição relativamente privilegiada na estrutura ocupacional, levando alguns estudiosos à previsão de que o comportamento dessas camadas tenderá ao conservadorismo, um ponto que ganha relevância à medida que, no capitalismo contemporâneo, perfis de inserção profissionais próximos ao conceito proposto por Goldthorpe se multipliquem ${ }^{12}$. Por outro lado, as desvantagens e precariedades associados aos "labor contracts" ajudam a explicar o contínuo apoio de parcelas dos trabalhadores às propostas igualitárias da esquerda (EVANS, 2000, p. 407). Ainda segundo Evans, a mudança em direção a formas mais sofisticadas de mensurar as divisões de classe nas sociedades contemporâneas foi acompanhadar também por um esforço de construção de medidas mais acuradas destinadas a traduzir com maior riqueza a complexidade do espectro político com o qual se defronta o cidadão nos episódios eleitorais, para além da original dicotomia esquerda-direita. O problema relacionado ao uso da dicotomia mencionada seria análogo ao já apontado quando da discussão sobre a classe: mudanças na composição interna de cada um dos pólos poderiam conduzir a inferências espúrias acerca de alterações no próprio conteúdo de classe do voto. Outra insuficiência relacionada vem a ser o fato de que modelos calcados em estruturas partidárias/classistas dicotômicas "impedem a observação de quaisquer processos de realinhamentos [em termos da relação partidos-classes]" (EVANS, 2000, p. 407). Deve-se salientar aqui a

12 Ou seja, no interior do grande grupo dos empregados, perfis de classe assalariada, nos termos das posições de classe examinadas. Os principais trabalhos de referência aqui são Goldthorpe, J. et al (1980) e Clarendon e Erickson, R. e Goldthorpe, J. (1992). 
importante observação metodológica recordada pelo autor: o conceito de realinhamento implica alterações no padrão de associação entre classe social e sufrágio sem que isso necessariamente pressuponha ou embuta "qualquer mudança na força dessa associação" (EVANS, 2000, p. 407). Em outras palavras, o fenômeno do realinhamento por si só não autoriza inferências quer sobre dealignment quer sobre um aumento da própria associação voto-classe, mas só pode ser discernido quando se abandonam os esquemas dicotômicos herdados dos estudos tradicionais. Finalmente, embora o presente artigo não aprofunde a questão, é patente não só para Evans como para os demais autores estudados, a superioridade dos modelos multivariados de regressão logística sobre os modelos baseados nas variáveis dicotômicas do tipo Alford para fins de estimação da relação classe-voto (EVANS, 2000, p. 407-8; MANZA, HOUT e BROOKS, 1995, p. 153-55).

Utilizando, em diferentes graus, as inovações metodológicas assinaladas, parcela importante dos estudos recentes sobre a relação voto-classe nas democracias avançadas vem produzindo conclusões notavelmente diferentes frente àquelas geradas pela literatura anterior, usuária de técnicas estatísticas com base nos modelos dicotômicos discutidos (EVANS, 2000, p. 408). Uma primeira onda relevante de estudos apoiada nessas novas abordagens procurou delinear os padrões de associação entre voto e classe social na Grã.Bretanha ${ }^{13}$, chegando à conclusão de que as evidências empíricas são descritas mais adequadamente mediante a noção de "trendless fluctuation" - isto é, flutuações globais no nível geral do voto de classe sem que se delineiem com clareza, pelo menos até o presente, tendências de longo prazo nesse movimento ${ }^{14}$. ou, alternativamente, mediante a junção à última noção de um reconhecimento de um declínio localizado no voto de classe, ocorrido nos anos 1960, sem que essa queda prosseguisse nas décadas subsequentes (one-off change). Outros estudos vêm sugerindo a existência nos Estados Unido ${ }^{15}$ de processos de realinhamento classe-partido e de incremento da clivagem de classe entre a parcela do eleitorado que comparece às urnas e aquela que não exerce efetivamente o seu direito de voto, com o aumento na proporção de membros das "middle-classes" no primeiro segmento, eleitoralmente ativo, e de pessoas pertencentes às "working-classes" no contingente dos que optam pela abstenção (EVANS, 2000, p. 409). Do ponto de vista dos realinhamentos, Evans enfatiza uma clara divisão no interior das classes médias, perceptível com o auxílio do esquema de Goldthorpe: enquanto estratos profissionais pertencentes à classe assalariada e os "routine white-collar workers" aproximam-se cada vez mais dos Democratas, autônomos e indivíduos responsáveis por funções gerenciais (esses

13 Referências dessa primeira onda de estudos que incorporam técnicas estatísticas mais avançadas são Heath (1985). e Evans et al (1991).

${ }^{14}$ Da literatura revalorizadora da classe examinada por esse artigo, a defesa direta dessa posição aparece em Manza e Brooks (1996, p. 720-1) e em Manza, Hout e Brooks (1995, p. 157-8).

15 O trabalho chave aqui é o de Hout et al (1995). 
últimos também parte da chamada 'classe assalariada') solidificam seus vínculos com o Republicanismo. Outras pesquisas concordam com a inexistência de padrões convergentes quanto à relação classe-voto em diferentes países, o que se torna possível de visualizar mediante o uso de técnicas estatísticas não-dicotômicas; nesse sentido, aponta-se incremento no voto classista na Grã-Bretanha, entre os anos 1940 e 1950, seguido de declínio nos anos 1960, em contraste com a trajetória de constância dessa associação na Alemanha e na França, excetuada apenas pelo realinhamento à direita dos fazendeiros e agricultores franceses (EVANS, 2000, p. 409) ${ }^{16}$. Exceção ao padrão seria a Noruega, onde se verificaria um declínio do voto classista entre as décadas de 1950 e 1990 do século XX. A ironia, conforme acentua Evans, é que esse declínio foi motivado, muito provavelmente, pelo sucesso de uma típica política de classe - a universalização da legislação de bem-estar -, que, paulatinamente, erodiu a oposição das classes médias à social-democracia ${ }^{17}$.

Evans (2000) também faz referências a estudos sobre divisões sociais e voto nas antigas sociedades comunistas da Europa do Leste, as quais, desde o final dos anos 1980, experimentaram um dramático processo de transição rumo às estruturas de mercado em um contexto de progressiva democratização política ${ }^{18}$. Para o autor, situações de explosiva ruptura como a vivenciada por esses países. em que se estilhaçam, em uma velocidade espantosa, padrões de renda e de inserção no trabalho, estilos de vida e expectativas sobre o futuro - ensejam a transformações igualmente rápidas nas linhas de clivagens sociais e no mapa de interesses e preferências políticas, emprestando à mudança social um ritmo que desafia a sabedoria convencional das ciências sociais. Mencionando expressamente o caso da República Tcheca, como exemplo das transformações no Leste Europeu, e a própria trajetória da Rússia pós-soviética, o autor sublinha as conclusões centrais de trabalhos que se debruçaram sobre essas experiências, as quais apontam a emergência de substantivas polarizações de classe, refletidas nas preferências políticas paulatinamente alinhadas em um eixo esquerda-direita similar ao do Ocidente industrializado, processo que tomou forma na medida em que cresceu a percepção dos diferenciados e desiguais custos e benefícios associados à transição para o mercado (cf. EVANS, 2000, p. 410).

Em um balanço global desse conjunto de trabalhos recentes, todos apoiados por metodologias aperfeiçoadas frente à geração anterior de estudos, Evans conclui que não há como falar de "um declínio generalizado da base de classe do voto nas

\footnotetext{
16 Sobre o ponto, ver Evans (1999); Weakliem \& Heath (1999).

17 Sobre a Noruega, ver Ringdal. e Hines (1999) e Esping-Andersen e Korpi (1984).

18 Quanto às transformações no antigo mundo comunista e suas implicações no que concerne à emergência de uma nova estrutura de clivagens nesses países, com substantivas consequências no plano da dinâmica político-eleitoral, ver Evans (1997); Evans e Whitefield (1999); Mateju et al (1999); Szelenyi et al (1998)
} 
sociedades industriais avançadas" (Evans, 2000, p. 410). A exceção seriam os países escandinavos - os quais, porém, transitariam de um nível atipicamente alto do voto de classe para patamares similares aos do restante das democracias ocidentais maduras, tornando-se, nesse sentido, mais homogêneos frente ao conjunto das experiências examinadas. Na realidade, em direção contrária ao consenso dos anos 1980/90, seria plausível hoje sustentar o argumento a respeito de uma intensificação da política de classe, em função dos sinais que se captam na Europa do Leste e na Rússia Pós-Soviética, que dão testemunho, para esses países, de um renascimento das polarizações de classe traduzidas politicamente em um espectro esquerda-direita ${ }^{19}$.

Mapeando novas questões e rumos imprimidos ao debate voto-classe, Evans salienta dois eixos interessantes abertos à discussão contemporânea (EVANS, 2000, p. 410-2). O primeiro deles ressalta a necessidade de uma reflexão teórica mais substantiva a respeito das cadeias de causalidade entre alterações nas estruturas de classe das sociedades industriais avançadas e mudanças nas preferências políticas dos respectivos eleitorados, o que, em termos teóricos mais gerais, remete ao debate estrutura-agência, tópico de relevo para a reflexão sociológica corrente ${ }^{20}$. Para Evans, durante muito tempo prevaleceu uma orientação determinista/estruturalista na matéria: mudanças na natureza e na estrutura das classes sociais conduziriam, em um maior ou menor espaço de tempo, a modificações na dinâmica política dos sistemas democráticos. Uma guinada, porém, rumo a orientações mais sensíveis à ação dos agentes, pode ser detectada

19 Manza, Hout e Brooks (1995) e Manza e Brooks (1996) também resumem, mas de forma menos detalhada, as conclusões da literatura recente sobre voto e classe que se vale de métodos estatísticos mais sofisticados. Já Martin Elff (2007, p. 279-84), estudando países europeus, sustenta uma perspectiva diferente na medida em que, por um lado, constata, para vários casos, o declínio tendencial do voto de classe, negando, no entanto, a perda da importância dessa categoria na estruturação das preferências político-eleitorais. Trabalhando com dados do Eurobarômetro para sete países (Bélgica, Dinamarca, França, Grã-Bretanha, Itália, Países Baixos e Alemanha Ocidental), Elff avalia a relevância político-eleitoral de dois tipos de clivagens sociais, a saber, as clivagens concernentes à classe social e aquelas relacionadas à dicotomia confessional/secular. No que concerne às clivagens de classe, tema que interessa mais de perto ao presente artigo, suas conclusões apontam para a continuada importância, até os dias de hoje, desse tipo de divisão social na dinâmica política das democracias estudadas, ainda que, quando projetados os dados no tempo, se reconheça o seu declínio relativo, pelo menos para alguns países. Assim, por um lado, a origem do apoio aos partidos trabalhistas, social. democráticos e/ou de orientação centro-esquerdista mostra, ainda para o período 1995-2002, marcadas diferenças em termos de classe. Trabalhando com a já referida classificação de Goldthorpe, Elff indica que, para a maior parte dos países examinados, a diferença, no apoio aos partidos inclinados à esquerda, entre trabalhadores ("working-class") e membros da classe assalariada ("the salariat", composta por profissionais e gerentes/administradores) e do grupo dos autônomos alcança, em média, significativos 20 pontos percentuais, mostrando que na virada do milênio as constituencies partidárias mantêm laços específicos com determinados estratos sociais. Por outro lado, no entanto, quando avaliadas essas diferenças no decorrer de três décadas (1975-2002), há claros sinais de declínio do voto de classe, notavelmente para a Dinamarca, Grã-Bretanha e Países Baixos. A Bélgica surge como uma exceção pela estabilidade de seus números no período.

20 Um bom resumo das perspectivas sobre o tema estrutura-agência na ciência política contemporânea pode ser encontrado em McAnulla (2002, p. 271-291). 
na literatura mais recente (EVANS, 2000, p. 410-1). Nesse sentido, vários trabalhos, ecoando os argumentos clássicos de Sartori (1969) e Przeworski (1989), vêm procurando sugerir que a estratégia dos partidos - isto é, suas estruturas organizacionais, suas plataformas políticas e apelos, o caráter das políticas públicas efetivamente desenvolvidas quando no governo etc - exercem efeitos sobre a própria constituição das bases de classe do voto. Em consequência, as mudanças e oscilações na trajetória do nível de voto de classe e nas clivagens classistas detectadas na parcela absenteísta do eleitorado (no caso específico dos Estados Unidos) são, em certo grau, produto também das opções partidárias, em vez de meramente refletirem movimentos tectônicos da estrutura social ${ }^{21}$. Trata-se, porém, de matéria aberta à controvérsia, não sendo possível detectar um claro consenso entre os estudiosos ${ }^{22}$.

O segundo eixo de discussão salientado por Evans (2000) relaciona-se ao esforço retomado por muitos autores, de identificação mais precisa dos mecanismos através dos quais a posição de classe pode conduzir a determinadas escolhas eleitorais, o que, a exemplo do primeiro eixo de debate, também se vincula a uma importante reflexão teórico-metodológica hoje em curso nas ciências sociais sobre o uso de mecanismos como ferramentas explicativas ${ }^{23}$. Nessa linha, estudos no âmbito interno à pesquisa sobre classe têm trazido à baila a importância de fatores como identidade (de classe e partidária), contextos sociais, redes de amizade e de influência interpessoal, defrontando-se, no entanto, muitas vezes, com problemas de endogeneidade, onde os pretensos fatores explicativos também requerem a remissão a causas anteriores. Notáveis também têm sido as tentativas de combinar explicações baseadas no cálculo racional e na identidade, onde se destacam os achados quanto às percepções diferenciadas dos eventos econômicos por atores posicionados distintamente no espectro de classes, levando a diferenças na opção eleitoral, bem como a compreensão mais acurada dos efeitos do decorrer

${ }^{21}$ Exemplos de pesquisas sobre o ponto são Kitschelt (1994) e Quaile Hill e Leighley (1996). Em sentido contrário: Dalton (1996).

22 Dos autores enfocados, Martin Elff (2007, p. 289) é o que mais enfatiza o papel ativo dos partidos na formatação das clivagens sociais: "[é evidente] que os partidos não são apenas passivos, objetos imutáveis das avaliações e atitudes dos eleitores; [ao contrário] eles estão ativamente buscando o seu apoio. Ao fazê-lo, os partidos assumem posições e propõem políticas que afetarão de forma diferenciada eleitores com distintas características sociais. Em consequência, as ações partidárias na competição por votos fazem diferença para a [maior ou menor] relevância das clivagens sociais. Aqui é possível seguir Converse que, em 1958, percebeu que 'o impacto do status sobre a decisão eleitoral depende do grau em que os partidos políticos oferecem (...) alternativas de políticas polarizadas', o que leva a concluir que as mudanças observadas no voto de classe podem ser atribuídas à ação dos partidos políticos e a outros fatores políticos". Dando um passo à frente nesse argumento, uma das conclusões sustentadas por Elff é que as alterações na relevância eleitoral das clivagens sociais são menos um efeito de longo prazo de transformações estruturais da sociedade, como defenderam Franklin e Mackie (1998), do que o resultado de escolhas políticas feitas ao longo do tempo por partidos no contexto da competição eleitoral (ELFF, 2007, p. 289).

$23 \mathrm{Um}$ autor central nessa discussão sobre mecanismos na teoria social em geral é Jon Elster, destacando-se, entre vários trabalhos, o seu Explaining Technical Change, publicado em 1983 pela Cambridge University Press. 
do ciclo de vida na auto-identificação classista, com uma tendência a um "desconto" maior do futuro por parte de grupos de idade mais avançada (EVANS, 2000 , p. 412). A tarefa essencial, aqui, no entanto - para que se alcance o objetivo de articular mais claramente padrões agregados de comportamento com seus micro-fundamentos - parece consistir, segundo o próprio Evans, no investimento em um maior diálogo, por parte dos estudiosos da classe, com os estudos convencionais do comportamento eleitoral, os quais, desde as tradições de Columbia e Michigan até os mais recentes modelos como o de Warren Miller e Merrill Shanks ${ }^{24}$, têm armazenado um importante acervo de conhecimentos sobre o assunto, e entende a decisão do voto, particularmente no caso da última dupla de autores referidos, como resultado de uma cadeia causal-temporal mediada por vários fatores e com efeitos de influência recíproca.

Expostos, em linhas gerais, os contornos básicos da literatura que vem procurando revalorizar a noção de classe como elemento estruturante da dinâmica política contemporânea, desloco o foco, a partir daqui, para o trabalho de van der Waal, Achterberg e Houtman (2007, p. 403-26), considerado como um exemplo concreto das possibilidades inventivas e originais dos estudos aqui resenhados. Criticando também a base metodológica da geração anterior de pesquisas sobre sufrágio e classe, esses autores propõem a distinção entre voto econômico de classe e o que denominam de cultural voting, diferenciando mecanismos explicativos e sustentando a relevância atual da classe social para a compreensão dos processos eleitorais correntes.

Nesse sentido, van der Waal, Achterberg e Houtman (2007, p. 405.6) iniciam sua reflexão questionando a própria suposição - presente, segundo eles, tanto em textos que acusam o declínio do voto de classe como em parcela dos que rejeitam essa conclusão - de que seria adequado mensurar o voto de classe mediante a aferição da intensidade da relação bivariada entre a posição de classe (definida em termos econômicos através do uso de uma composição de medidas que combinam, em geral, renda, ocupação e educação) e o comportamento eleitoral. O problema crucial, detalhado a frente, estaria no uso conjunto das medidas anteriormente citadas, o que tende a transformar o indicador do voto de classe em uma "caixa preta" que camufla e mistura dois mecanismos explicativos radicalmente diferentes. Ao não diferenciar, involuntariamente, entre esses dois mecanismos (vinculados a domínios valorativos distintos, como se discutirá adiante), o Índice Alford e indicadores dele derivados, para o trio de autores referido, não conseguem expressar o que pretendem, a saber, que as escolhas eleitorais são motivadas por preferências embasadas na posição de classe que demandam políticas redistributivas (caso das classes trabalhadoras) ou que as

${ }^{24}$ Em se tratando de Miller e Shanks, a referência essencial vem a ser a coletânea, de 1996, intitulada The New American Voter, publicada pela Harvard University Press. 
rechaçam (caso das "middle-classes"). Na verdade, não logram fazê-lo não tanto porque o voto não expresse interesses econômicos, mas porque são incapazes de especificar e diferenciar outros drives importantes do sufrágio no pós-Segunda Guerra.

A falha crucial da utilização da relação bivariada nos termos convencionais relaciona-se ao fato de que ao construir os indicadores de classe ela pretende mensurar a relação classe-comportamento político sem distinguir, entre valores econômicos e valores político-sociais, os quais, aliás, como é sabido na literatura, conformam distintos domínios de valores não necessariamente relacionados do ponto de vista da população em geral. Assim, para a crítica da utilização da relação aludida, os autores partem das conclusões bem conhecidas de Lipset e de Inglehart, produzidas, respectivamente, nos anos 1950 e 1970, sobre o conservadorismo social das classes trabalhadoras e a emergência de um eixo de valores pós-materialistas nas classes médias ${ }^{25}$. Organizando as ideias em um duplo eixo econômico e social, os autores mencionam inicialmente a perspectiva de Lipset. Nos termos extraídos diretamente desse último:

"o liberalismo econômico refere-se às questões convencionais relativas à
redistribuição de renda, status e poder entre as classes. Os mais pobres em
todos os lugares são mais liberais ou esquerdistas em tais questões. (...).
Por outro lado, quando o liberalismo é definido em termos não-econômicos -
de forma a [relacionar-se], por exemplo, com direitos civis para dissidentes
políticos, direitos civis para minorias étnicas e raciais, políticas externas
internacionalistas e legislação liberal de imigração - a correlação é
revertida" 26 (LIPSET, 1959, p.485, apud van DER WAAL,
ACHTERBERG e HOUTMAN, 2007).

Para van der Waal, Achterberg e Houtman (2007), contudo, ainda que não seja possível negar a existência de relação entre liberalismo/conservantismo social e posições de classe (convencionalmente definidas), não há simetria entre essa relação e a que tradicionalmente é postulada no domínio dos valores econômicos. $\mathrm{E}$ isso por uma razão muito simples: não é a renda ou as categorias ocupacionais que explicam uma posição, por exemplo, mais tolerante ou liberal no domínio dos valores sociais ou sociopolíticos, mas o nível de educação ${ }^{27}$. É evidente que, em

25 As referências aqui são Lipset (1959) e Inglehart (1977).
26 Note-se que “liberalismo econômico", no texto, significa uma posição reformista e redistributiva no
plano econômico, refletindo o jargão predominante nos Estados Unidos, não tendo qualquer parentesco
com o sentido emprestado à expressão no Brasil.
27 "O liberalismo econômico da classe trabalhadora, (...) [consistente com a postura sustentada pelos estudos
convencionais], pode efetivamente ser explicado pelos seus interesses econômicos [de cunho classista]. É
precisamente sua vulnerabilidade econômica - sua baixa renda, dependência salarial, insegurança no emprego, 
geral, níveis baixos de educação ou capital cultural se associam, grosso modo, com patamares reduzidos de renda e, quando está em jogo apenas o posicionamento diante de valores econômicos, podem ser utilizados como proxies da posição de classe. No entanto, quando lidamos também com o domínio dos valores sociopolíticos, a perspectiva dos autores é que é preciso distinguir entre classe em um sentido econômico e a noção de capital cultural, atributo variável dependente do nível de educação a que o indivíduo teve acesso (van DER WAAL, 2007, p. 405-8) ${ }^{28}$. Apesar disso, e essa é a crítica dos autores, tem sido padrão na literatura sociológica e, particularmente nos estudos de classe, combinar medidas de ocupação, educação e renda na construção de indicadores de status socioeconômico ou posição de classe (van DER WAAL, ACHTERBERG e HOUTMAN, 2007, p. 407), o que é profundamente equivocado quando da análise das tendências da sociedade contemporânea - inclusive no que interessa aqui, a saber, o debate sobre os padrões de classe do voto.

Essencialmente, o problema assinalado pelos autores consiste no seguinte: as tradicionais relações bivariadas entre posição de classe (construídas a partir das medidas mencionadas anteriormente) e comportamento eleitoral terminam por misturar ("mixing up") o voto de classe e o que eles denominam de voto cultural. Nos termos do texto, o tipo bivariado convencional de associação, presente na maior parte dos estudos, não diferencia entre:

"o voto de classe, isso é, o voto por um partido de esquerda (direita) fundado no liberalismo econômico (conservadorismo), o qual se enraiza em uma posição frágil (forte) de classe, com (...) o voto cultural, isso é, o voto por um partido de direita (de esquerda) fundado no conservadorismo social (liberalismo social), o qual se enraiza em uma quantidade limitada (ampla) de capital cultural. O último tipo de voto

e baixo nível de educação - que leva membros da classe trabalhadora a defender o liberalismo econômico. 0 conservadorismo social da classe trabalhadora, por outro lado, não pode ser explicado por sua posição de fragilidade na vida econômica. Nem baixas rendas, dependência salarial ou insegurança no emprego produzem conservadorismo social, [o qual está ligado, na verdade, e de modo muito forte] (...) a baixos níveis educacionais. (...). [Por sua vez] Aqueles que abraçam o liberalismo social (...) não são (...) os economicamente privilegiados, (...) mas [distintamente] aqueles que possuem amplo capital cultural" (van DER WAAL, ACHTERBERG \& HOUTMAN, 2007, p. 407).

28 "[Numerosos] estudos enfatizam que não são principalmente os que têm níveis baixos de renda que são socialmente conservadores, mas, diversamente, os que possuem precário nível educacional. Inversamente, não é o rico, mas a pessoa [de nível educacional relativamente mais elevado] que invariavelmente se revela menos conservadora [do ponto de vista social], mais tolerante frente aos não-conformistas e menos preconceituosa [em termos raciais]. Em outras palavras, se concebemos as classes como categorias ocupacionais que diferem, obviamente, de modo substantivo com respeito à educação também não devemos nos surpreender [ao nos depararmos] com uma classe trabalhadora mais liberal economicamente $e$ conservadora do ponto de vista social do que as classes médias, mas isso não significa que [as diferenças nos domínios econômico e social] possam ser ambas explicadas pela classe em um sentido econômico" (van DER WAAL, ACHTERBERG \& HOUTMAN, 2007, p. 406). 
precisa ser distinguido do primeiro, [uma vez que] é movido por uma motivação cultural e não por uma motivação econômica, derivando-se do capital cultural em vez de [originar-se] da classe em um sentido econômico, [produzindo] pressões cruzadas [sobre o] eleitorado [que contradizem] os interesses econômicos lastreados na classe" (van DER WAAL, ACHTERBERG e HOUTMAN, 2007, p. 408).

Ao incorrer nessa justaposição involuntária, indicadores baseados na relação bivariada terminam dizendo muito pouco sobre o querem medir, posto que as forças que permanecem camufladas dentro da "caixa preta" trabalham em direções opostas, podem possuir graus de vigor diferentes, em desiguais conjunturas históricas e, adicionalmente, variam independentemente uma da outra. Um exemplo ajuda a ilustrar o que os três autores querem sugerir: uma substantiva preferência por políticas públicas igualitárias e redistributivas, no plano econômico, lastreada em uma posição inferior na estrutura de classe, conducente, portanto, a um voto na esquerda, em tudo harmônica com as hipóteses sobre o voto classista, pode perfeitamente ser anulada ou contrabalançada por uma igualmente forte tendência, decorrente de limitado estoque de capital cultural, pelo sufrágio à direita, lastreado em altos níveis de conservadorismo social (van DER WAAL, ACHTERBERG e HOUTMAN, 2007, p. 408). Deixando de separar os tipos de voto, abordagens convencionais conduzem "facilmente (...) à conclusão equivocada de que a classe não influencia o voto" (van DER WAAL, 2007, p. 408). Na verdade, reconhecendo realinhamentos importantes no período pós-Segunda Guerra . sintetizados em um afastamento relativo das "working-classes" frente à esquerda e das "middle-classes" em relação aos agrupamentos partidários direitistas -, os autores não descartam, em princípio, a possibilidade de uma efetiva tendência de longo prazo a um declínio do voto de classe nas democracias avançadas. Mais provável, no entanto, para os autores, é que o chamado voto cultural tenha ganhado vigor nesse período, sem que necessariamente tenha ocorrido o mencionado declínio (é possível, inclusive, para eles, que o voto classista tenha ganho fôlego, o que não seria contrário à evidência empírica se fosse possível demonstrar um avanço ainda maior do cultural voting). Algumas conclusões sólidas emergentes de variadas pesquisas reforçariam essa possibilidade: em primeiro lugar, o fato de que estudos que definem a classe em termos de renda e não a partir de outras medidas têm concluído pelo reforço, desde os anos 1940, da política de classe, o que se harmoniza com o argumento do texto, uma vez que a adoção da renda permite evitar o problema do mixing up entre voto econômico e voto cultural, pois, como anotado, não há relação direta (não mediada pela educação) entre aquela variável e o conservadorismo/liberalismo social. Em segundo lugar, um declínio tendencial por décadas do voto de classe sugeriria certo eclipse das questões referidas ao 
conflito distributivo pelo produto econômico, o que está longe de refletir o curso dos debates nas democracias pós-1945, em particular após a intensificação do processo de globalização; de outra parte, não há muita controvérsia acerca da maior saliência paulatinamente assumida no período por questões concernentes ao domínio cultural e sociopolítico, o que, novamente, carrearia peso para a tese do incremento da importância relativa do voto cultural. Por fim, não tem sido possível para as abordagens convencionais, com base em seus próprios parâmetros, predizer períodos e países em que a relação entre voto e classe é mais fraca, o que talvez incentive hipóteses que associem intervalos de enfraquecimento de voto de classe com conjunturas de saliência especial dos níveis de cultural voting, tornando necessária a introdução desse último fator para a compreensão do primeiro fenômeno (van DER WAAL, ACHTERBERG e HOUTMAN, 2007, p. 409-10).

Trabalhando com uma amostra de 15 países, para o período 1956-1990, e lidando com praticamente a mesma base empírica ${ }^{29}$ utilizada pelo influente estudo de Nieuwbeerta ${ }^{30}$, que concluiu pelo declínio do voto de classe, van der Waal, Achterberg e Houtman (2007), testam duas hipóteses e chegam a conclusões notavelmente diversas, confirmando as considerações teóricas delineadas acima. A primeira hipótese testada verifica se um declínio do voto classista, no sentido econômico antes especificado, efetivamente teria ocorrido. Ela é estruturada de forma a fazer a previsão de que o declínio na relação entre posição de classe (mensurada em termos convencionais) e o voto foi causado por uma diminuição tanto na tendência dos segmentos que auferem menores níveis de renda em votar pela esquerda como na propensão das parcelas mais privilegiadas em termos de renda em votar pela direita. A segunda hipótese verifica se um aumento no voto cultural teria se processado no período histórico em tela. Ela postula que o declínio na relação entre posição de classe (mensurada em termos convencionais) e o voto foi causado por uma diminuição da propensão tanto dos mais bem-educados (detentores de maior estoque de capital cultural) para votar pela direita quanto dos menos bem-educados (precário nível de capital cultural) para sufragar a esquerda. Note-se que as hipóteses são construídas para separar os dois tipos de votos (econômico/classista e cultural) associados a domínios valorativos distintos e independentes (econômico e social ou sociopolítico). Os resultados a que os autores chegam confirmam suas previsões: a primeira hipótese é rejeitada, indicando que,

29 Os países incluídos na amostra são os seguintes: Austrália, Áustria, Bélgica, Canadá, Dinamarca, Finlândia, França, Alemanha, Grã-Bretanha, Irlanda, Itália, Países Baixos, Noruega, Suíça e Estados Unidos. Os dados analisados correspondem a mais de 93.000 entrevistados, distribuídos pelos países referidos (van DER WAAL, ACHTERBERG e HOUTMAN, 2007, p. 410-1).

30 Os principais trabalhos de Paul Nieuwbeerta referidos são The Democratic Class Struggle in Twenty Countries, 1945-1990. Amsterdan, Thesis Publishers, de 1995, e, com Harry Ganzeboom, "International Social Mobility and Politics File: Documentation of an Integrated Dataset of 113 National Surveys Held in 16 Countries, 1956-1991". Amsterdan. Steinmetz Archive/SWIDOC Amsterdan Steinmetz archive codebook, 1996. 
para o intervalo de tempo e os países considerados, a tendência do voto à direita (esquerdista) aumenta (diminui) com o nível da renda, não podendo o declínio tendencial do voto de classe (mensurada a classe em termos convencionais) ser explicado por uma diminuição no voto de classe em sentido econômico. A segunda hipótese, ao contrário, é validada pela análise estatística, a qual mostra que, desde a Segunda Guerra, há uma tendência à diminuição no voto conservador por parte dos estratos detentores de alto capital cultural acompanhada por um aumento da propensão ao voto nesses partidos - de direita - por parte das camadas de mais baixa educação. $O$ aumento no cultural voting, e não a diminuição do voto econômico de classe, explicaria, por conseguinte, a tendência ao declínio da relação entre classe (medida em sentido convencional) e o voto (van DER WAAL, ACHTERBERG e HOUTMAN, 2007, p. 415-6). Na verdade, livrando-se do linguajar equívoco da pesquisa convencional, os autores concluem que os realinhamentos partidários em curso desde o pós-1945 não indicam declínio do voto de classe - mensurada essa categoria por nível de renda - mas tão-somente o crescente peso do voto cultural, ancorado em diferenças educacionais, que coexiste com as clássicas influências decorrentes da estrutura de estratificação social.

\section{Referências Bibliográficas}

ALFORD, R. Party and Society: The Anglo-American Democracies. Westport, CT: Greenwood, 1963.

.Class Voting in Anglo-American Political Systems. In:

LIPSET, S. e ROKKAN, S. (orgs). Party Systems and Voter Alignments: Cross-National Perspectives. New York: Free, 1967.

CLARENDON e ERICKSON, R. e GOLDTHORPE, J. The Constant Flux: A Study of Class Mobility in Industrial Societies. Oxford: Clarendon Press, 1992.

CLARK, T. e LIPSET, S. "Are Social Classes Dying?" International Sociology, v.6, nº 4 , 1991.

CREWE, I. "On the Death and Resurrection of Class Voting: Some Coments on How Britains Votes". Political Studies, n 34, 1986. 
DALTON, R. Citizen Politics: Public Opinion and Political Parties in Advanced Industrial Democracies. Chatham: Chatham House, 1996.

DOWNS, A. An Economic Theory of Democracy. New York: Harper \& Row, 1957.

ELFF, M. "Social Structure and Electoral Behavior in Comparative Perspective: The Decline of Social Cleavages in Western Europe Revisited". Perspectives on Politics, v. $5,02,2007$.

EVANS, G. "Class Inequality and the Formation of Political Interests in Eastern Europe”. European Journal of Sociology, v.38, 1997.

(org.). The End of Class Politics? Class Voting in Comparative Context.

Oxford: Oxford University Press, 1999.

"The Continued Significance of Class Voting". Annual Review of Political

Science, v.3, 2000.

EVANS, G. et al. "Modelling Trends in The Class/Party Relationship, 1964-87".

Electoral Studies, v.10, 1991.

EVANS, G. e WHITEFIELD S. The Emergence of Class Politics and Class Voting in Post-Communist Russia". In: EVANS, G. (org.). The End of Class Politics?. Oxford University Press, 1999.

FRANKLIN, M. e MACKIE, T. "Electoral Change in Western Countries: Consequences of Post-Industrial Social Change". In: NORRIS, P. (org). Elections and Voting Behaviour. Aldershot: Dartmouth/Ashgate, 1998.

FRANKLIN, M., MACKIE, T. et al. Electoral Change: Responses to Evolving Social and Attitudinal Structures in Western Countries. Cambridge: Cambridge University Press, 1992.

GOLDTHORPE J et al. Social Mobility and Class Structure in Modern Britain. Oxford: Clarendon Press, 1980.

HEATH, R. et. al. How Britain Votes. Oxford: Pergamon, 1985.

HOUT, M. et al. "The Democratic Class Struggle in the United States". American Sociological Review, v.60, 1995

INGLEHART, R. The Silent Revolution: Changing Values and Political Styles among Western Public. Princenton, NJ: Princenton University Press, 1977. 
INGLEHART, R. Culture Shift in Advanced Industrial Society. Princeton: Princeton University Press, 1990.

KITSCHELT, H. The Transformation of European Social Democracy. Cambridge: Cambridge University Press, 1994.

LANE, J. e ERSON, S. Politics and Society in Western Europe. London: Sage, 1994.

LIPSET, S. "Democracy and Working-Class Authoritarianism". American Sociological Review, v.24, nº 1959.

LIPSET, S; LAZARSFELD, P.; BARTON, A. e LINZ, J. The Psychology of Voting: An Analysis of Political Behaviour. In: LINDZEY, G. (org.). Handbook of Social Psychology. Cambridge: Addison-Wesley, 1954.

LIPSET, S. e ROKKAN, S. Cleavage Structures, Party Systems and Voter Alignments: an Introduction. In: LIPSET, S. e ROKKAN, S. (orgs.). Party Systems and Voter Alignments: Cross National Perspectives. New York: Free, 1967.

LISTHAUG, O. The Decline of Class Voting. In: STROM, K. e SVASAND, L. (orgs.). Challenges to Political Parties: The Case of Norway. Ann Arbor: University of Michigan Press, 1997.

MANZA, J.; HOUT, M. e BROOKS, C. "Class Voting in Capitalist Democracies since World War II: Dealignment, Realignment, or Trendless Fluctuation?" Annual Review of Sociology, v. 21, 1995.

MANZA, J. e BROOKS, C. "Does Class Analysis Still Have Anything to_Contribute to the Study of Politics?" Theory and Society, v.25, n. 5, 1996.

MATEJU, P. et al. The Politics of Interests and Class Realignment in the Czech Republic, 1992-96. In: EVANS, G. (org.). The End of Class Politics?. Oxford: Oxford University Press, 1999.

MCANULLA, S.D. Structure and Agency. In: MARSH, D. and STOKER, G. (orgs.) Theory and methods in political science. Palgrave Macmillan, 2002.

NIEUWBEERTA, P. The Democratic Class Struggle in Twenty Countries, 1945-1990. Amsterdan: Thesis Publishers, 1995. 
PZREWORSKI, A. Capitalismo e Social Democracia. São Paulo: Companhia das Letras, 1989.

QUAILE HILL, K. e LEIGHLEY, J. "Political Parties and Class Mobilization in Contemporary United States Elections". American Journal of Political Science, $\mathrm{n}^{\circ} 40$, 1996.

RINGDAL, K. e HINES, K. Changes in Class Voting in Norway 1957-1989. In: EVANS, G. (org.). The End of Class Politics?. Oxford: Oxford University Press, 1999.

ROSE, R. e MCALLISTER, I. Voters Begin to Choose: From Closed Class to Open Elections in Britain. Beverly Hills: Sage Publishing, 1986.

SAINSBURY, D. "Class Voting and Left Voting in Scandinavia: The Impact of Different Operationalizations of the Working Class". European Journal of Political Research, v.15, 1987.

SARTORI, G. From the Sociology of Politics to Political Sociology. In: LIPSET, S. (org.). Politics and the Social Sciences. Oxford: Oxford University Press, 1969.

SZELENYI, I. et al. "Left Turn in Post-Communist Policies? Bringing Class Back". East European Politics and Societies, v.11, 1998.

van DER WAAL, J.; ACHTERBERG, P. e HOUTMAN, D. "Class Is Not Dead - It Has Been Buried Alive: Class Voting and Cultural Voting in Postwar Western Societies (1956-1990)". Politics \& Society, v. 35, n. 3, 2007.

WEAKLIEM, D. \& HEATH, A. The Secret Life of Class Voting: Britain, France, and the United States: definitions, models, and data. In: EVANS, G. (org.). The End of Class Politics?. Oxford: Oxford University Press, 1999.

Sérgio Eduardo Ferraz - seferrazz@uol.com.br

Recebido para publicação em outubro de 2008.

Aprovado para publicação em julho de 2009. 